\title{
TCOM \\ Boundary spanners and thinking partners: adapting and expanding the research-practice partnership literature for public engagement with science (PES)
}

\section{Karen Peterman, Sarah Garlick, John Besley, Sue Allen, Kathy Fallon Lambert, Nalini M. Nadkarni, Mark S. Rosin, Caitlin Weber, Marissa Weiss and Jen Wong}

\begin{abstract}
This paper is the culmination of several meaning-making activities between an external researcher, PES practitioners, and social scientist researchers who considered the unique contributions that can be made through RPPs on PES (that is, research-practice partnerships on public engagement with science). Based on the experiences from three RPP projects, the group noted that the PES context may be particularly suited to RPPs, and identified the importance of working as thinking-partners who support reciprocal decision-making. Recommendations are made in support of using these approaches to advance practical knowledge-building and reduce shared frustrations about the disconnect between research and practice in PES.
\end{abstract}

Keywords

Public engagement with science and technology; Scholarly communication

DOI

https://doi.org/10.22323/2.20070801

Submitted: 6th June 2021

Accepted: 1st September 2021

Published: 8th November 2021

Introduction

Innovative and effective public engagement with science (PES) calls for an understanding of the PES literature, practical skills and expertise, and rigorous evaluation. Among those in the PES research community there is frustration that theory and evidence are not informing PES practice [Besley, 2015; Jensen and Gerber, 2020; Scheufele et al., 2021]. Simultaneously, there is frustration among practitioners that PES research is not useful to their work [Besley, Dudo, Yuan and Abi Ghannam, 2016]. Underlying these frustrations, however, is a shared interest in PES as a vehicle for strengthening the relationships between scientific communities and broader society. The expectation is that strong relationships can help ensure that society benefits from scientific advancement and that science advances in ways that align with societal needs and values [Besley, O'Hara and Dudo, 2019].

Partnerships between PES researchers and practitioners represent one way to meet this challenge by bridging the divide between research and practice. 
We describe learning from three projects that used a research-practice partnership (RPP) approach to advance PES. RPPs are defined in the education field as "long-term mutually beneficial formalized collaborations between education researchers and practitioners... for producing more relevant research, improving the use of research evidence in decision making, and engaging both researchers and practitioners to tackle problems of practice" (National Network of Education Research Practice Partnerships, https:/ / nnerpp.rice.edu/). The literature on RPPs spans a number of disparate fields, in addition to education, including health care, urban planning, and criminology [Coburn and Penuel, 2016; Coburn, Penuel and Geil, 2013]. There also exists a growing literature on museum-based collaborations, with some of the best-known cases shared in Sobel and Jipson [2016]. Such collaborations take a range of trajectories, and are typically characterized by an increasing alignment of goals as partnerships develop iteratively, with practitioners' experiences and researchers' theoretical framings shaping each other over time [Callanan, Martin and Luce, 2016]. These reciprocal interactions allow the joint work of RPPs to be owned and shared by all [Coburn, Penuel and Geil, 2013]. When successful, RPPs produce relevant, actionable research and solutions, and provide individual benefits for practitioners (e.g., self-reported improvements in evaluation processes, opportunities for staff professional development, and inspiration for new topics and approaches) as well as researchers (e.g., participant access, opportunities for student training, and inspiration for new research directions) [Callanan, 2012; Coburn, Penuel and Geil, 2013; Corriveau et al., 2016; Haden et al., 2016; Jipson and Sobel, 2016; Rhodes and Bushara, 2016].

Among the challenges of sustaining RPPs are the often-disparate pace of research and practice [Legare, Gose and Guess, 2016], as well as institutional drivers such as the degree to which there is institutional buy-in and support [Coburn, Penuel and Geil, 2013; Coburn and Penuel, 2016; Farrell, Harrison and Coburn, 2019; Haden et al., 2016]. Other challenges relate to the cultural, professional, and organizational boundaries that are encountered within RPPs [Penuel et al., 2015]. Researchers and practitioners tend to come from "different cultural worlds" [Coburn, Penuel and Geil, 2013], thus a key role for many successful RPPs is that of the boundary spanner. Boundary spanners are conceptualized as the "brokers" [Davidson and Penuel, 2019] and "sojourners" [Risien, 2019] who facilitate the exchange of knowledge and ideas across boundaries, and who orchestrate, over time, the development of trusting relationships [Haymore Sandholtz and Finan, 1998; Bednarek et al., 2018; Goodrich et al., 2020]. By developing a "dual vantage point" [Davidson and Penuel, 2019, p. 162] and understanding the dynamics of both worlds, boundary spanners take an active role in translating goals and perspectives across the divides of research and practice. Research on boundary spanning has included RPPs in K12 education contexts that spanned the cultures of classrooms, schools, districts, academic departments, and funding priorities [Penuel et al., 2015]; science and policy interactions that facilitated knowledge exchange among scientists, decision-makers, and stakeholders to ultimately support evidence-informed decision-making [Bednarek et al., 2018; Goodrich et al., 2020]; and the multi-directional exchanges among researchers, PES practitioners, and publics to broaden the societal impacts of research [Risien, 2019].

Despite the growing literature on RPPs and the role of boundary spanners, these concepts are still underexplored in the field of PES. Using examples and learning from three recent RPPs for PES, we demonstrate the utility of this approach in the 
contexts of informal learning and science communication. We then expand on the RPP literature by illustrating an evolution in these RPPs toward a style of informal interactions that bridge research and practice beyond the joint work of the RPP, as PES researchers and practitioners call on each other to apply existing scholarship and experiential knowledge to support one another's work. These insights demonstrate the potential for the field of PES to make significant contributions to our understanding of RPPs, and the potential for critical approaches to RPPs to make significant contributions to the field of PES.

The three projects that informed this paper included RPPs to study programs aimed at fostering high-quality PES experiences. The National Science Foundation's Advancing Informal Science Learning program funded all three and we focus on them because of their noteworthy pairing of PES practitioners with social scientists. In the contexts of our projects, one social scientist and one practitioner from each project team served as boundary spanners. These roles were distinct from those of other social scientists and practitioners who were part of the larger project team. Each project is introduced below, followed by a brief description of their underlying theoretical frameworks.

Guerilla Science creates event-based encounters that serve people who do not see science as being "for them" [Bisbee O'Connell et al., 2020]. These events occur in the places where science is least expected, including cultural venues like music and arts festivals, county fairs, and disused urban spaces [Rosin et al., 2021]. The RPP for this project, ongoing since 2017, focused on how the transdisciplinary integration of science and art, writ large, can support increased access to and learning in STEM [Bevan et al., 2019]. The partnership drew on the literature on STEM Learning Ecosystems [Barron, 2006; National Research Council, 2015], to provide a framework to contextualize the impact of short-term pop-up interventions. It also drew on research on storyworlds, specifically their role in creating meaning for and forging connections with learners [Avraamidou and Osborne, 2009; Joubert, Davis and Metcalfe, 2019], and festivals, specifically the affective role of carnival in circumventing social barriers to engagement [Bakhtin, 1984].

PES@LTERs is a project to understand and advance PES within Long Term Ecological Research (LTER) programs, using the Hubbard Brook Ecosystem Study in New Hampshire and the Harvard Forest in Massachusetts [Besley et al., 2021]. This ongoing RPP began in 2017. Project activities have focused on developing the capacity for effective PES, embedded within the organizational cultures and practices of these long-term research programs. These include pathways for scientists to build relationships with stakeholders and community members, co-design and co-produce knowledge and tools with stakeholders and community members, reach broader audiences, and engage within their organizations to reflect on their goals for and experiences with PES. The partnership drew on the literature of strategic science communication [Besley, O'Hara and Dudo, 2019] and the Theory of Planned Behavior and related Integrated Behavioral Model [Montaño and Kasprzyk, 2015] to investigate scientists' beliefs about PES to inform future organizational-level interventions for improving PES activities at LTER sites. It also drew on the literature of participatory research [McBride et al., 2017] and 
actionable knowledge and environmental policy [Cash et al., 2003; Driscoll, Fallon Lambert and Weathers, 2011] in its design of PES pathways.

The STEM Ambassador Program (STEMAP) was developed to guide scientists to engage with members of the public, with an emphasis on building relationships with people who do not or cannot engage with science in traditional learning venues such as museums and schools [Nadkarni et al., 2019]. STEMAP integrates existing informal science education models and training to widen the venues in which engagement occurs (e.g., correctional facilities, senior centers, local businesses, and parks). Scientists build skills to form community partnerships, learn about the community they wish to engage, and design engagement projects that align with the community's interests, values, and experiences. STEMAP drew from the literature on impact identity and engagement objectives to guide scientists to leverage their research, personal interests, and experiences for engagement and to set appropriate engagement objectives [Besley, Dudo and Yuan, 2018; Risien and Storksdieck, 2018]. The program was also informed by the literature addressing exclusion in science communication to consider venues for engagement [Dawson, 2018], design thinking to develop engagement projects specific to participants [Goldman, 2017], and science of learning literature to implement projects [National Research Council, 2009; Selvakumar and Storksdieck, 2013].

Two practitioners and one researcher from each RPP participated in the development of this paper. All responded individually to a set of interview questions (for a total of nine interviews) and then participated in a series of group-level meaning-making activities that were led by the first author, an external researcher. These activities included synchronous video-conference discussion sessions and asynchronous group exchanges via email and Google Documents. In reflecting on their past and current experiences, the authors noted the ways that their experiences confirmed scholarship on RPPs conducted in other educational contexts and offered new perspectives on how and why RPPs might serve as an effective approach for PES. These reflections are summarized below in relation to three main ideas.

\section{Idea \#1: PES is particularly suited to the boundary spanning inherent in successful RPPS}

RPPs are collaborations between key players from different but related sectors. Penuel et al. [2015] note that "some cultural boundaries are more easily crossed than others" [p. 188]. Shared beliefs about how to make meaning from evidence and overall scientific values are also characteristics that support successful RPPs [Bevan, 2017; Tseng, Fleischman and Quintero, 2018]. Our conversations indicated that PES projects may provide an ideal set of stakeholders for the RPP approach, in part based on the professional cultures shared by PES researchers and practitioners (i.e., cultures where evidence derived from scientific research is key). Further, the very existence of RPPs for PES is predicated on a shared interest in fostering positive audience-specific experiences and outcomes.

Though our projects were not selected with this characteristic in mind, all of the PES practitioners who participated in our RPPs were trained as graduate-level natural scientists originally, and now identify as PES practitioners. This is not typical of RPPs in other contexts (e.g., education). These similarities seem likely to 
provide lower barriers to establishing respect and trust. We expect that many PES practitioners were also trained in the sciences - this is true for PES-related trainers in North America, at least [Dudo, Besley and Yuan, 2021] — and that this provides a relatively narrow boundary to span when compared to other educational contexts. This does not mean that the work is easy. It simply means that the hurdles may be lower or fewer in number. These shared values might also set the stage for identifying the boundary spanners needed to support the joint work across the divides of PES practice and social science research. Haden et al. [2016] noted that their RPP success was partly based on having both a researcher and a practitioner who were committed to the relationship. This was also the case for our RPPs on PES, with one practitioner taking a deeper dive into the PES literature and becoming the primary research collaborator. We posit that the shared scientific values between PES researchers and practitioners might make this role easier to achieve in RPPs for PES.

Publications and conference presentations are a common and meaningful professional currency for both groups, and PES practitioners and researchers are likely to recognize the multiple ways that data and funding can sustain PES programs. PES practitioners and researchers also have shared skills to contribute to these endeavors. The current literature on RPPs is skewed toward researcher perspectives [Bevan, 2016]. PES practitioners may be poised to make unique contributions to the RPP literature, in particular, by publishing work that shares the practitioner side of the story. In the case of our RPPs, one of the three projects has made progress in this area by prioritizing publications that feature practitioners as the first author.

\section{Idea \#2: there is a progression of partnerships among RPPs for PES}

Our RPPs for PES shared common partnership journeys, replicating characteristics from the existing RPP literature in a new context. The earliest phase of the journey involved the researcher working as an observer to understand the project context. In the case of Guerilla Science, for example, the researcher spent a year building an understanding of the project to identify appropriate connections to the literature. Bevan et al. [2021] demonstrates how this RPP applied separate frameworks related to science and art practices to study the STEAM experiences of Guerilla Science, with the goal of learning how this analytical approach might inform the design of future events.

\footnotetext{
Talking to [the researcher] about her perspective of what Guerilla Science is doing in the various contexts we operate in was definitely a new perspective for me to think about in terms of what Guerilla Science is achieving. We have a vision, we have a mission... when you apply social science frameworks to that I think it really strengthens the overall justification. - Guerilla Science practitioner
}

The initial relationship and trust building needed for a productive RPP also happened during this phase, verifying the importance of creating shared language within the context of RPPs for PES. Bevan [2017] notes the importance of good chemistry for successful RPPs as the basis for "building a trusting relationship that has parity" [p. 139], as well as enriched professional relationships and networks. Each of the quotes below exemplify these characteristics, as well as respect, 
humility, and curiosity, which have also been identified as core values for successful RPPs [Tseng, Fleischman and Quintero, 2018].

\begin{abstract}
I personally really enjoy working with her... One of the things that's worked really well is that I feel very respected in the interactions. I feel like my opinions are valued and used. - Guerilla Science practitioner, reflecting on a research partner Working with [my practitioner colleague], that was a big draw... I think it was exciting for the ecologists to work with their peer ecologists, across sites... [and then also] just engaging with [our research colleague] and learning from him and having him on the team. - PES@LTER practitioner, reflecting on the project team I've never met anyone quite like her... She really steps outside the box just all the time, and so this project is sort of a manifestation of that vision. - STEMAP researcher, reflecting on a practitioner partner
\end{abstract}

Once the initial learning phase was accomplished, our RPPs for PES divided time between two interaction strategies. The first was that of co-designers of research to explore PES strategies. This role was described by Bevan and Penuel [2018] as involving processes of iteration, where questions and strategies are developed, tested, reviewed, and retested. Such collaboration has also been described as jointly negotiated research with integrated roles [Allen and Gutwill, 2016] or as collaborative partnership [Haden et al., 2016], in which a community of researchers and practitioners unite around a common focus of study. This role is a defining feature of RPPs and thus an expected outcome of these projects.

That iterative, data-driven process - it's the great equalizer. It always catches things that are really important. So then I can let go more easily of the things that I wish they did a little differently. — STEMAP researcher

Social science has really moved up in my vision, my understanding of them as contributing equally to the understanding of the world... So many hardcore biologists or hardcore physicists used to scorn social scientists... but that is a sign of someone who is ignorant of what it means to collaborate with social scientists. - STEMAP practitioner

The second interaction strategy was that of "thinking partner", a role we have not seen developed in the literature. This strategy, discussed below, was critical for all three RPPs for PES.

\title{
Idea \#3: acting as a "thinking partners provides a distinct opportunity for collaboration
}

A key aspect of these research collaborations was a role of "thinking partner", which is an understudied role that we define as being characterized by as-needed, informal thought work to apply existing knowledge and expertise across partnership boundaries beyond the primary project focus of the RPP. These reciprocal interactions focused on the application of existing research and practitioner logic to support each other's individual thinking and work, rather than the formal study of that application through new collaborative research (i.e., the joint work that is typically a defining feature of RPPs). Practitioners relied on researchers to suggest concepts, models, and theories that might be applied to decisions that needed to be made; and researchers relied on practitioners to groundtruth the relevance of their research questions, help interpret ambiguous observations, and foreground potential research gaps. These thinking partner 
interactions were enabled by the boundary spanning functions of the RPP, yet this role seemed distinct from the role of boundary spanners, who facilitate the mutual understanding required for thinking partners to emerge. Our boundary spanners all served as thinking partners for one other. Importantly, a wider network of researchers and practitioners associated with each project have also participated in and benefited from thinking partner collaborations. Thinking partner interactions were described as follows:

\begin{abstract}
Once we started working together, now we do work together (without funding) in small ways. We do work on each other's projects [and the RPP] was essential for catalyzing time together... the trust and relationships are just so critical, and having something you both care about is so critical, that you share an interest. - Guerilla Science researcher

Speaking as an ecologist I think we scientists tend to be sort of practitioners in that we kind of have a gut feeling of like what's the next question or how do I apply this... I think practitioners going to theory is often predicated or preceded by uncertainty about what they should do next to make it more generalizable or more accessible or more workable. - STEMAP practitioner
\end{abstract}

The researchers and practitioners from all three projects agreed that being thinking partners for one another was just as meaningful to them as the research collaborations that are the traditional RPP focus. The role of thinking partner has received little attention in the literature, though there are hints of its potential in some descriptions. In reflecting on her career conducting research in museums, Gaskins [2016] noted several ways that she has benefited from these collaborations. Among them she noted an appreciation for having the opportunity to share her outsider perspective to help elucidate the assumptions the museum was making about its visitors, paired with an increased awareness of the difficulty in transferring research to practice and the additional work needed on the part of researchers to help navigate this space. Also, in their work on role and identity negotiation within an education RPP, Farrell and colleagues [2019] describe the emergence within the RPP over time of "a critical friend role" [p. 8] and the role of "a thought partner/advisor that provided guidance" [p. 9].

The quotes below exemplify the influence of collaborating as thinking partners on practice in one case and on research in another. Neither quote is based on instances of conducting a formal research study; instead, both are based on collaborating as thinking partners.

One of the things we realized from [the researcher] was that our objectives weren't really strong and clear. We have been able to look at the literature that he sent us to examine more closely what our goals versus objectives have been. And so now we'll be taking those recrafted, more clear objectives and implementing those. So to me that's been kind of a very beautiful little dance that we hadn't anticipated [in which] researchers of science communication kind of layer their questions and their expertise onto the implementation of our program. - STEM Ambassador Program practitioner

You'll be a better, more engaged researcher. You will be doing more impactful research. A lot of the research that I do is at a national level. So I'm surveying scientists from across the country. [PES@LTERs] is place-specific. It's grounded. In terms of understanding science communication, I feel like this [approach] helps. _ PES@LTER researcher 
Time is needed to build relationships and to collaborate regularly to build the relationship of thinking partners. In the case of our three RPPs, the practitioner who functioned as the boundary spanner had paid time to work with their research partner to consider how existing literature applied to their specific PES context. In the examples studied here we also noted that it was seasoned rather than junior faculty who had the flexibility to devote the time needed to think in partnership with practitioners. The exchange below exemplifies the privileged roles that are at liberty to embrace the RPP approach.

\begin{abstract}
It's a team-based approach... [and] it takes time to build a team. You have to negotiate the roles. Within a team there might be a few boundary spanners who are closer to the boundary... I felt a dedication and an interest and a connection to [the researcher's] literature... I had a lot of time written into my NSF grant... And now I'm feeling the crunch because as my grant winds down, I have to be a lot more careful about that. I can't spend three quarters of my week in scholarship mode. I think there's a crunch on practitioners in particular to be able to play that thinking partner role. It is a privilege. Not all practitioners are going to be able to just be a thinking partner all the time. PES@LTERs practitioner

And I think [the] privilege on my side is that I'm a full professor with tenure and support. To some extent I can do whatever I think is useful... Junior scholars generally can't. And I don't think I had the breadth of experience to be able to do this when I was starting out. Junior scholars may not be as able to commit to projects that aren't focused on a discrete concept or hypothesis where you can feel confident you're going to get a publishable result. _- PES@LTERs researcher
\end{abstract}

Discussion and conclusions
This paper includes the perspectives of both researchers and practitioners from three RPPs for PES who came together to share reflections with each other and with the science communication field. The insights provide a unique contribution to the existing literature by focusing on RPPs for PES directly. The experiences of these three teams verify the existing literature within the context of PES and suggest that RPPs for PES are poised to make contributions to scholarship in this area. The role of thinking partner also emerged as a key interaction strategy for RPPs for PES. The thinking partner role is an under-studied type of collaboration that may occur within, and perhaps independent of, a RPP. This role is distinct from that of boundary spanners who might undertake a number of different strategies to facilitate cross-boundary connections, including a lead role in formulating research studies that define an RPP.

We found that the shared cultures of PES practitioners with science backgrounds and PES researchers may provide fewer barriers to finding productive middle ground compared to RPPs in other contexts. All of our PES practitioners, for example, identified themselves as scientists in earlier stages of their careers. We expect that this may be a common path among PES practitioners, and that these shared experiences enable boundary spanning and thinking partner work. Because PES practitioners and researchers share professional currencies such as grants and publications, and because both groups have been trained to generate these types of products, RPPs for PES are positioned to make unique contributions to the literature by providing first-author perspectives from both sides of the boundary. This work holds the potential to help deepen science communication research by generating practically useful knowledge, while also enhancing theory and 
scholarship. The kinds of collaborative cross-training that happens at the boundary also has the potential to impact the broader work conducted by researchers and practitioners.

Effective partnerships, including RPPs, are long-term undertakings. Looking for thinking partners may be one way to begin this process. We encourage PES practitioners and researchers to consider whether there are already collaborators in their network who can be supported as thinking partners to help span the boundaries of PES planning, implementation, evaluation, and research. As stated by one of our practitioner authors, these approaches might be a fit for "anyone who is suitably aware of their own limitations". More specifically, ideal boundary spanners and thinking partners are those who have: demonstrated respect, humility, cross-discipline curiosity in their work; a commitment to systematic observation and analysis that includes an openness to alternate hypotheses; and a willingness to participate in optimistic dialogue and negotiation [Tseng, Fleischman and Quintero, 2018]. Boundary spanner and thinking partner roles can be articulated in project goals and objectives, planned for in the scope of work, and should be incorporated into project budgets.

Many university-based researchers and practitioners are likely to find potential thinking partners across a range of campus-based contexts including social science and education departments, broader impacts offices, PES centers, and evaluation centers. Colleagues based in university centers may be poised to serve as curators since their job descriptions often include facilitating networking and co-learning [Risien, 2019]. A recent landscape study outlined such supports, as well as some of the systemic constraints that prevent PES collaborations [Risien and Nilson, 2018]. Conferences, professional societies, and science communication networks are also venues for finding like-minded collaborators; indeed, two of our three RPPs for PES include partners who met for the first time at professional meetings. Yet another option is to convene a panel of visitors to identify and learn from collaborators. Both the STEMAP and PES@LTERs projects convened "peer review meetings" of engagement practitioners and researchers to provide feedback on their programs. These meetings helped the programs' leadership shape future work, identify collaborators, and discern knowledge gaps. Online think tank sessions might be used by those who do not have a budget to support formal gatherings for this purpose. Regardless of whether and how researchers and practitioners convene, process-based research that focuses on how researchers and practitioners navigate supports and barriers as they use RPP, boundary spanning, and thinking partner approaches seems needed.

Our three projects each worked at the research-practice boundary to generate knowledge for the broader PES field to provide strategies to promote inclusive science communication across a range of strategies, including: broadening the theoretical perspectives used to explore PES [Bevan et al., 2019], developing specific strategies to promote co-production with a range of priority populations [Garlick et al., 2019], and setting direct intentions in identifying priority populations for PES [Nadkarni et al., 2019; Weber, Allen and Nadkarni, 2021]. RPP partners included those trained originally in communications, ecology, environmental studies, physics, psychology, and the philosophy and sociology of science. Their collective work has contributed to literature directed at scientists, informal science educators, and science communicators. Our RPPs did not include publics in their boundary 
spanning work. We are intrigued by the potential of including this broader range of perspectives in the joint work of boundary spanners and thinking partners, particularly in response to the need for inclusive science communication and PES research [Canfield et al., 2020]. Forging these collaborations has implications for obtaining funding as well as for intellectual enrichment. The NSF AISL program that supported our RPPs, for example, only funds PES programming in the service of exploring research questions about informal STEM learning.

The idea of thinking partners may be extended to areas outside of the RPP context. We chose the term thinking partner intentionally to denote an active and ongoing engagement. The current paper serves as another example of this role. The perspectives presented here were collected and summarized in a six-month time frame, which is relatively short by academic standards. Our work was informed by several academic literatures including K-12 education, informal learning, PES, and policy and management. None of us knows all of these literatures. By coming together as thinking partners to write this article, we did not have to. Instead, we were able to leverage the separate but related areas of expertise represented across our author team. This process was efficient and generative, allowing our group to make contributions to both academic and practical knowledge-building.

We encourage other PES researchers and practitioners to consider both practical and academic knowledge-building in their work as well. Bridging this divide is at the heart of the thinking partner role and sharing perspectives about this divide is part of what made this role so valuable to our RPP teams. Practical knowledge-building also requires practical communication and dissemination strategies, so that those who are not part of a thinking partner collaboration can learn from those able to work in this space. Research briefs are a promising practice in this area, as they are short distillations of research accompanied by relevant applications of that research. The Exploratorium museum and the RR2P project (Relating Research To Practice) have both published research briefs that serve as models for this approach (see https:/ / www.exploratorium.edu/education/ california-tinkering-afterschool-network-research-practice-resource-collection and http://rr2p.org/briefs for examples). We encourage PES researchers and practitioners to budget for and allocate time to developing and sharing these types of products. Further, we encourage publication venues to promote this practice by either requiring or accepting research or practice briefs as supplemental documents that can be shared alongside academic publications. To model this recommendation, our team of authors has created an open-access practice brief to accompany this article. It can be found on the Center for Advancing Informal Science Learning web site (CAISE, https: / / www.informalscience.org/). We hope that others in the PES community will find inspiration in the experiences we have shared here to create and share their own collaborations that strive to span the boundaries between PES research and practice.

Acknowledgments We would like to thank Bronwyn Bevan for her contributions as a thinking partner on this work. We also thank Tracey Martin and Sarah Hughes from RMC Research Corporation for their contributions to the interview protocol and interviews with the PES@LTERs team. 
Funding

acknowledgment
Guerilla Science is funded by the National Science Foundation (award 1647150).

The PES@LTERs project is funded by the National Science Foundation (collaborative awards 1713204, 1713307, 1713197, 1713222, and 1713219). The STEM Ambassador Program is funded by the National Science Foundation (awards 1514494 and 1906408).

\section{References}


Bevan, B., Mejias, S., Rosin, M. and Wong, J. (2021). 'The main course was mealworms: the epistemics of art and science in public engagement'. Leonardo 54 (4), pp. 456-461. https : //doi.org/10.1162/leon_a_01835.

Bevan, B. and Penuel, W. R., eds. (2018). Connecting research and practice for educational improvement: ethical and equitable approaches. New York, NY, U.S.A.: Routledge. https://doi .org/10.4324/9781315268309.

Bevan, B., Peppler, K., Rosin, M., Scarff, L., Soep, E. and Wong, J. (2019). 'Purposeful pursuits: leveraging the epistemic practices of the arts and sciences'. In: Converting STEM into STEAM programs: methods and examples from and for education. Ed. by A. J. Stewart, M. P. Mueller and D. J. Tippins. Cham, Switzerland: Springer, pp. 21-38.

https://doi.org/10.1007/978-3-030-25101-7_3.

Bisbee O'Connell, K., Keys, B., Storksdieck, M. and Rosin, M. (2020). 'Context matters: using art-based science experiences to broaden participation beyond the choir'. International Journal of Science Education, Part B 10 (2), pp. 166-185. https://doi.org/10.1080/21548455.2020.1727587.

Callanan, M. A. (2012). 'Conducting cognitive developmental research in museums: theoretical issues and practical considerations'. Journal of Cognition and Development 13 (2), pp. 137-151. https://doi.org/10.1080/15248372.2012.666730.

Callanan, M. A., Martin, J. and Luce, M. (2016). ‘Two decades of families learning in a children's museum: a partnership of research and exhibit development'. In: Cognitive development in museum settings: relating research and practice. Ed. by D. M. Sobel and J. L. Jipson. New York, NY, U.S.A.: Routledge. https://doi.org/10.4324/9781315667553-7.

Canfield, K. N., Menezes, S., Matsuda, S. B., Moore, A., Mosley Austin, A. N., Dewsbury, B. M., Feliú-Mójer, M. I., McDuffie, K. W. B., Moore, K., Reich, C. A., Smith, H. M. and Taylor, C. (2020). 'Science communication demands a critical approach that centers inclusion, equity and intersectionality'. Frontiers in Communication 5, 2. https://doi.org/10.3389/f comm.2020.00002.

Cash, D. W., Clark, W. C., Alcock, F., Dickson, N. M., Eckley, N., Guston, D. H., Jäger, J. and Mitchell, R. B. (2003). ‘Knowledge systems for sustainable development'. Proceedings of the National Academy of Sciences 100 (14), pp. 8086-8091. https://doi.org/10.1073/pnas. 1231332100.

Coburn, C. E. and Penuel, W. R. (2016). 'Research-practice partnerships in education: outcomes, dynamics, and open questions'. Educational Researcher 45 (1), pp. 48-54. https://doi.org/10.3102/0013189x16631750.

Coburn, C. E., Penuel, W. R. and Geil, K. E. (2013). Research-practice partnerships: a strategy for leveraging research for educational improvement in school districts. New York, NY, U.S.A.: William T. Grant Foundation.

Corriveau, K. H., Kipling, R., Ronfard, S., Biarnes, M. C., Jeye, B. M. and Harris, P. L. (2016). 'The Living Laboratory ${ }^{\circledR}$ model: a mutual professional development model for museum-based research partnerships'. In: Cognitive development in museum settings: relating research and practice. Ed. by D. M. Sobel and J. L. Jipson. New York, NY, U.S.A.: Routledge, pp. 65-83. https://doi.org/10.4324/9781315667553-9.

Davidson, K. L. and Penuel, W. R. (2019). 'The role of brokers in sustaining partnership work in education'. In: The role of knowledge brokers in education: connecting the dots between research and practice. Ed. by J. Malin and C. Brown. London, U.K.: Routledge, pp. 154-167. https://doi.org/10.4324/9780429462436-11. 
Dawson, E. (2018). 'Reimagining publics and (non) participation: exploring exclusion from science communication through the experiences of low-income, minority ethnic groups'. Public Understanding of Science 27 (7), pp. 772-786. https://doi.org/10.1177/0963662517750072.

Driscoll, C. T., Fallon Lambert, K. and Weathers, K. C. (2011). 'Integrating science and policy: a case study of the Hubbard Brook Research Foundation Science Links program'. BioScience 61 (10), pp. 791-801. https://doi.org/10.1525/bio.2011.61.10.9.

Dudo, A., Besley, J. C. and Yuan, S. (2021). 'Science communication training in North America: preparing whom to do what with what effect?' Science Communication 43 (1), pp. 33-63. https://doi .org/10.1177/1075547020960138.

Farrell, C. C., Harrison, C. and Coburn, C. E. (2019). "What the hell is this, and who the hell are you?" Role and identity negotiation in research-practice partnerships'. AERA Open 5 (2), pp. 1-13. https://doi.org/10.1177/2332858419849595.

Garlick, S., Fallon Lambert, K., Weiss, M. and Besley, J. C. (2019). 'Embedding co-production into long term ecological research: insights from Hubbard Brook and Harvard Forest'. PA31H-1092. In: AGU Fall Meeting (San Francisco, CA, U.S.A. 9th-13th December 2019).

Gaskins, S. (2016). 'Collaboration is a two-way street'. In: Cognitive development in museum settings: relating research and practice. Ed. by D. M. Sobel and J. L. Jipson. New York, NY, U.S.A.: Routledge, pp. 151-170. https://doi.org/10.4324/9781315667553-15.

Goldman, S. (2017). 'Design thinking'. In: The SAGE encyclopedia of out-of-school learning. Ed. by K. Peppler. SAGE Publications.

Goodrich, K. A., Sjostrom, K. D., Vaughan, C., Nichols, L., Bednarek, A. and Lemos, M. C. (2020). 'Who are boundary spanners and how can we support them in making knowledge more actionable in sustainability fields?' Current Opinion in Environmental Sustainability 42, pp. 45-51. https://doi.org/10.1016/j.cosust.2020.01.001.

Haden, C. A., Cohen, T., Uttal, D. H. and Marcus, M. (2016). 'Building learning: narrating experiences in a children's museum'. In: Cognitive development in museum settings: relating research and practice. Ed. by D. M. Sobel and J. L. Jipson. New York, NY, U.S.A.: Routledge, pp. 84-103. https://doi .org/10.4324/9781315667553-10.

Haymore Sandholtz, J. and Finan, E. C. (1998). 'Blurring the boundaries to promote school-university partnerships'. Journal of Teacher Education 49 (1), pp. 13-25. https://doi.org/10.1177/0022487198049001003.

Jensen, E. A. and Gerber, A. (2020). 'Evidence-based science communication'. Frontiers in Communication 4, 78. https://doi .org/10.3389/f comm. 2019.00078.

Jipson, J. L. and Sobel, D. M. (2016). 'The interaction between research and practice in museum settings: an introduction and synthesis'. In: Cognitive development in museum settings: relating research and practice. Ed. by D. M. Sobel and J. L. Jipson. New York, NY, U.S.A.: Routledge, pp. 1-12. https://doi.org/10.4324/9781315667553-5.

Joubert, M., Davis, L. and Metcalfe, J. (2019). 'Storytelling: the soul of science communication'. JCOM 18 (05), E. https ://doi .org/10.22323/2.18050501.

Legare, C. H., Gose, R. and Guess, C. (2016). 'Examining the development of scientific reasoning in context: a museum and laboratory partnership'. In: Cognitive development in museum settings: relating research and practice. Ed. by D. M. Sobel and J. L. Jipson. New York, NY, U.S.A.: Routledge, pp. 138-148. https://doi.org/10.4324/9781315667553-13. 
McBride, M. F., Lambert, K. F., Huff, E. S., Theoharides, K. A., Field, P. and Thompson, J. R. (2017). 'Increasing the effectiveness of participatory scenario development through codesign'. Ecology and Society 22 (3). https://doi.org/10.5751/es-09386-220316.

Montaño, D. E. and Kasprzyk, D. (2015). 'Theory of reasoned action, theory of planned behavior, and the integrated behavioral model'. In: Health behavior: theory, research, and practice. Ed. by K. Glanz, B. K. Rimer and K. Viswanath. 5th ed. San Francisco, CA, U.S.A.: Jossey-Bass/Wiley, pp. 95-124.

Nadkarni, N. M., Weber, C. Q., Goldman, S. V., Schatz, D. L., Allen, S. and Menlove, R. (2019). 'Beyond the deficit model: the ambassador approach to public engagement'. BioScience 69 (4), pp. 305-313. https://doi.org/10.1093/biosci/biz018.

National Research Council (2009). Learning science in informal environments: people, places, and pursuits. Ed. by P. Bell, B. Lewenstein, A. W. Shouse and M. A. Feder. Washington, D.C., U.S.A.: The National Academies Press. https://doi.org/10.17226/12190.

- (2015). Identifying and supporting productive STEM programs in out-of-school settings. Washington, DC, U.S.A.: The National Academies Press. https://doi.org/10.17226/21740.

Penuel, W. R., Allen, A.-R., Coburn, C. E. and Farrell, C. (2015). 'Conceptualizing research-practice partnerships as joint work at boundaries'. Journal of Education for Students Placed at Risk (JESPAR) 20 (1-2), pp. 182-197. https://doi.org/10.1080/10824669.2014.988334.

Rhodes, M. and Bushara, L. (2016). 'Learning about science and self: a partnership between the Children's Museum of Manhattan and the Psychology Department at New York University'. In: Cognitive development in museum settings: relating research and practice. Ed. by D. M. Sobel and J. L. Jipson. New York, NY, U.S.A.: Routledge, pp. 104-119. https://doi.org/10.4324/9781315667553-11.

Risien, J. (2019). 'Curators and sojourners in learning networks: practices for transformation'. Evaluation and Program Planning 73, pp. 71-79. https://doi.org/10.1016/j . evalprogplan.2018.12.001.

Risien, J. and Nilson, R. (2018). Coordinated reform and local solutions: transforming the university systems of reward and professional advancement. Corvallis, OR, U.S.A. https://doi.org/10.5399/osu/1134.

Risien, J. and Storksdieck, M. (2018). 'Unveiling impact identities: a path for connecting science and society'. Integrative and Comparative Biology 58 (1), pp. 58-66. https://doi.org/10.1093/icb/icy011.

Rosin, M., Wong, J., O'Connell, K., Storksdieck, M. and Keys, B. (2021). 'Guerilla science: mixing science with art, music and play in unusual settings'. Leonardo 54 (2), pp. 191-195. https://doi.org/10.1162/leon_a_01793.

Scheufele, D. A., Krause, N. M., Freiling, I. and Brossard, D. (2021). 'What we know about effective public engagement on CRISPR and beyond'. Proceedings of the National Academy of Sciences 118 (22), e2004835117. https://doi.org/10.1073/pnas.2004835117.

Selvakumar, M. and Storksdieck, M. (2013). 'Portal to the public: museum educators collaborating with scientists to engage museum visitors with current science'. Curator: The Museum Journal 56 (1), pp. 69-78. https://doi.org/10.1111/cura.12007.

Sobel, D. M. and Jipson, J. L., eds. (2016). Cognitive development in museum settings: relating research and practice. New York, NY, U.S.A.: Routledge. https://doi.org/10.4324/9781315667553. 
Tseng, V., Fleischman, S. and Quintero, E. (2018). 'Democratizing evidence in education'. In: Connecting research and practice for educational improvement: ethical and equitable approaches. Ed. by B. Bevan and W. R. Penuel. New York, NY, U.S.A.: Routledge, pp. 3-16. https : //doi .org/10 .4324/9781315268309-1. Weber, C., Allen, S. and Nadkarni, N. (2021). 'Scaling training to support scientists to engage with the public in non-traditional venues'. JCOM 20 (04), N02. https://doi.org/10.22323/2.20040802.

Authors

Dr. Karen Peterman is President of Karen Peterman Consulting, Co., an external evaluation and educational research consulting firm in Durham, NC. She studies informal science learning and science communication projects. Recent work has focused on using collaborative models to study evaluation methods and instruments and visitor studies that describe those who participate in events and event outcomes. E-mail: karenpetermanphd@gmail.com.

Dr. Sarah Garlick is the Director of Science Policy and Outreach for the Hubbard Brook Research Foundation, a support organization for the long-term Hubbard Brook Ecosystem Study in the White Mountains of New Hampshire. Sarah is a practitioner-scholar whose work focuses on advancing evidence-based public engagement programs within scientific research institutions.

E-mail: sgarlick@hubbardbrookfoundation.org.

Dr. John C. Besley is the Ellis N. Brandt Chair of Public Relations. He has published more than 100 articles and book chapters on science communication and public engagement. This work has included both research on public opinion about science and science communicators' views about public communication. He is the associate editor for risk communication for the journal Risk Analysis and on the editorial boards of Public Understanding of Science, Science Communication, Environmental Communication, and the Journal of Risk Research.

E-mail: jbesley@msu.edu.

Dr. Sue Allen is a Senior Research Scientist at the Maine Mathematics and Science Alliance. She studies learning in a variety of informal settings, including museums, libraries, and afterschool programs. Her current work includes using situational assessments to characterize the impacts of virtual professional learning in STEM. E-mail: sallen@mmsa.org.

Kathy Fallon Lambert is a Senior Advisor at the Center for Climate, Health, the Global Environment at the Harvard T.H. Chan School of Public Health where she focuses on the intersection of the science and policy of climate mitigation, environmental quality, and health. Previously she was the Science \& Policy Project Director at the Harvard Forest where she served as a principal investigator for the New England Scenarios, Services, and Society research project. Kathy was also the first executive director of the Hubbard Brook Research Foundation where she developed the Science Links program to connect ecosystem science with public policy. She holds a B.A. from Dartmouth College and a Master of Forest Science degree from the Yale School of Forestry and Environmental Studies. She is a Switzer Fellow, Leopold Schepp Scholar, and recipient of the U.S. EPA Environmental Merit Award. E-mail: kathleen.lambert3@gmail.com. 
Dr. Nalini Nadkarni is a biology professor and forest ecologist at the University of Utah. She studies the ecology of canopy-dwelling biota play in rainforest ecosystems. She also engages non-traditional public audiences such as faith-based groups, urban youth, artists, and people who are incarcerated with science and conservation. With recent support from the National Science Foundation, she co-developed the STEM Ambassador Program to train other scientists to carry out public engagement in venues where community groups live, work, and recreate. E-mail: nalini.nadkarni@utah.edu.

Dr. Mark Rosin is an associate professor of mathematics at the Pratt Institute and Executive Director at Guerilla Science, an international science and society organization. His work focuses on the connections between science, art, and culture, and their realizations in the public places and spaces that science is least expected. He is the winner of the Early Career Award for Public Engagement with Science from the American Association for the Advancement of Science and an Ashoka Foundation Emerging Innovator. E-mail: mark@guerillascience.org.

Caitlin Weber (M.S., University of Michigan) has a background in natural resources and science communication. She served as the Program Manager for the STEM Ambassador Program at the University of Utah from 2016-2021 where she provided training to support scientists in engaging with the public in non-traditional learning venues. E-mail: caitlinqw@gmail.com.

Dr. Marissa Weiss is an ecologist and science communication practitioner at Harvard Forest in Petersham, MA. She works at the interface of science, media, and policy to help scientists leverage the outcomes of their work for environmental solutions. Her current work focuses on building capacity for environmental researchers to develop and implement strategic engagement and communication initiatives. E-mail: marissaweiss@fas.harvard.edu.

Jen Wong is co-founder and Director of Guerilla Science, an organization dedicated to revolutionizing how people engage with science. She is also Head of Programming at Science Gallery London, King's College London. Jen has worked across the cultural sector, primarily in museums, galleries, higher education and music festival sectors. Her background is in exhibition curation and experience production. She holds a degree in Natural Sciences, and an M.Phil in History \& Philosophy of Science. E-mail: jen@guerillascience.org.

\section{How to cite}

Peterman, K., Garlick, S., Besley, J., Allen, S., Fallon Lambert, K., Nadkarni, N. M., Rosin, M. S., Weber, C., Weiss, M. and Wong, J. (2021). 'Boundary spanners and thinking partners: adapting and expanding the research-practice partnership literature for public engagement with science (PES)'. JCOM 20 (07), N01. https://doi.org/10.22323/2.20070801. 